\title{
Plasma Levels of Interleukin-6 and the Cluster of Differentiation 4/Cluster of Differentiation 8 Ratio in Frailty among Community-dwelling Older People
}

\author{
Sri Sunarti *(iD), Nurria Indriyaningrum ${ }^{2}$ (D), Cesarius Wahono $^{2}$ (D), Djoko Soeatmadji ${ }^{2}$, Achmad Rudijanto ${ }^{2}$ (D) \\ Retty Ratnawati ${ }^{3}$, Setyawati Soeharto Karyono ${ }^{4}$, Maryunani Maryunani ${ }^{5}$ (D) \\ ${ }^{1}$ Doctoral Program in Medical Sciences, Faculty of Medicine, Universitas Brawijaya, Malang, East Java, Indonesia; ${ }^{2}$ Department \\ of Internal Medicine, Faculty of Medicine, Universitas Brawijaya, Malang, East Java, Indonesia; ${ }^{3}$ Departement of Physiology, \\ Faculty of Medicine, Universitas Brawijaya, Malang, East Java, Indonesia; ${ }^{4}$ Departement of Pharmacology, Faculty of Medicine, \\ Universitas Brawijaya. Malang, East Java, Indonesia; ${ }^{5}$ Department of Economic, Faculty of Economics and Business, \\ Universitas Brawijaya, Malang, East Java, Indonesia
}

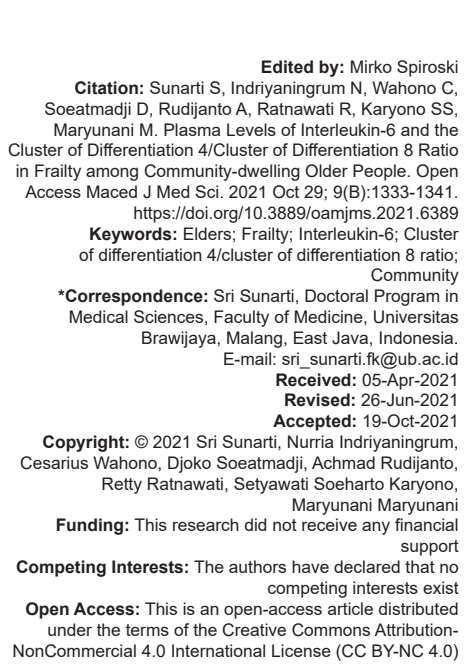

Abstract

BACKGROUND: Frailty has become a major health problem among Indonesian elders. Immunosenescence specifically inflammaging are essential components in the development of frailty. Early screening and timely tailored intervention may effectively prevent or delay the adverse outcomes in elders.

AIM: This study measured the cluster of differentiation (CD)4/CD8 ratio from the immunosenescence pathway and plasma interleukin (IL)-6 levels as inflammatory markers from the inflammaging pathway and observed the correlations between robust and frail elders groups.

METHODS: We conducted a cross-sectional survey. Using multistage random sampling, we enrolled 64 participants across Malang city, divided into frail and robust groups. We analyzed the plasma IL-6 levels and CD4/CD8 ratio using an independent t-test and the Mann-Whitney $U$ test.

RESULTS: Significant differences between frail and robust elders were found in age and education level, with the frail participants being older than the robust $(p=0.001)$ and lower educational level $(p<0.001)$. However, plasma IL-6 levels $(p=0.936)$ and the CD4/CD8 ratio $(p=0.468)$ were not statistically different between the groups.

CONCLUSION: Plasma level of IL-6 was found to increase similarly in both groups, while CD4/CD8 ratio was norma and not statistically different between the robust and frail group in elders.

\section{Introduction}

The increasing average life expectancy has contributed to the aging of the world's population [1]. By 2050 , approximately, $21.3 \%$ of the global population will be 60 years or older, up from $9.2 \%$ in 1990 [2]. Indonesia is home to the eighth largest population of older persons in the world and the fourth largest among Asian countries. With around 21 million older persons $(8.2 \%)$ in the population, Indonesia presents the largest number of older persons in Southeast Asia [2]. Frailty has become a major health problem among Indonesian elders. Frailty is defined as a state of reduced ability to recover from stress resulting from an age-related decline in reserves is highly prevalent in old age [3] and associated with a higher risk of all-cause mortality [4].
Asystematic review and meta-analysis involving data from more than 120,000 older adults from 28 countries, the incidence of frailty and pre-frailty were estimated as 43.4 and 150.6 new cases per 1,000 people per year [5]. According to Japan studies using the Cardiovascular Health Study criteria, the prevalence of frailty increases with age $(4.0 \%$ in the $65-74$ years age range, $16.2 \%$ in the $75-84$ years age range, and $34.0 \%$ among those aged $\geq 85$ years) [6], also found higher in woman than in men [3]. In Indonesia, the prevalence of frailty is $18.70 \%$ and $66.20 \%$ in prefrail conditions, and only $15.10 \%$ are fit/robust [7]. Meanwhile in Malang, the prevalence of frail was $35.4 \%$ and prefrail was $47.2 \%$, only $17.4 \%$ of the elderly were in a fit/robust condition [8].

Despite the importance, the underlying immune mechanisms contributing to frailty and particularly the pathways to chronic inflammation in older adults 
remain unclear. Many studies revealed that a particular immune senescence process termed inflammaging is essential in the development of frailty [9]. Inflammaging refers to a chronic low-grade inflammatory profile progressed with advancing age, and shown that the heightened inflammatory state in this regard may play a central role in the pathogenesis of pre-frailty and frailty, either by promoting protein degradation or through its deregulation of other metabolic pathways [10].

The previous study showed that aging has been associated with an increase in the serum levels of inflammatory biomarkers [11]. High levels of pro-inflammatory markers in the blood and other tissues are often detected in older individuals and can predict the risk of cardiovascular diseases, frailty, multi-morbidity, and declines in physical and cognitive function [12]. Several inflammatory markers were reported to be involved such as interleukin-6 (IL-6) and tumor necrosis factor-alpha (TNF- $\alpha$ ). IL- 6 is a soluble mediator of immune response and inflammation that is expressed in various tissues and up-regulated in the frailty as identified earlier. In response to inflammation and tissue injuries, IL-6 is promptly produced at inflammation sites and reaches the liver through the bloodstream, where it has multiple pleiotropic effects [13].

The age-associated loss of immunity known as immune senescence is strongly associated with higher vulnerability for severe infections, vaccine failure, and premature mortality in elders. Immune senescence is marked by a progressive decrease in the number of naive cells and an increase in the number of memory cells showing poor functionality. The differentiation of $\mathrm{T}$ cells toward a senescent phenotype is characterized typically by clonal expansion of cluster of differentiation (CD)8+ T lymphocytes that lack expression of CD28 [14]. A low or inverted CD4/CD8 ratio is an immune risk phenotype that is associated with altered immune function, immune senescence, and chronic inflammation. The prevalence of an inverted CD4/CD8 ratio increases with age [15].

Early screening and timely tailored intervention of frailty may effectively prevent or delay the adverse outcomes in older adults. In a bid to develop a deeper understanding of the association between immune senescence and immune aging-related chronic inflammation to the frailty in elder people, we aim to investigate the CD4/CD8 ratio and plasma IL-6 levels among the robust and frail elder population.

\section{Methods}

\section{Recruitment and selection of participants}

A cross-sectional study was conducted on older people in various stages of frailty, from non-frail to frail. Participants were recruited from five districts, and using multistage random sampling were chosen five sub districts, and then randomly chosen five two clusters among them, which are integrated at community-based integrated service center for older adults (Posyandu Lansia). Members who met the following criteria: 65 years of age or older and physically and cognitively able to complete the performance-based tests and the questionnaires. The exclusion criteria were severe movement disorders due to any medical condition or acute illness. Those who met the eligibility criteria were then interviewed and measured (Frailty Index based on Cardiovascular Health Study, and blood samples were taken. The aim was to recruit 32 volunteers per frailty stage (a total of 64 participants). They received written and verbal information about the study and then gave written informed consent to take part. The study was approved by the medical ethics committee of the Faculty of Medicine University of Brawijaya (number 378A/EC/KEPK/07/2015).

\section{Measurements}

The working definition of frailty was based on the Fried Criteria, which included weight loss, exhaustion or poor endurance (self-reported exhaustion), weakness (handgrip strength), slowness (gait speed), and low physical activity (kilocalories expended per week) [16]. The weight loss criterion comprised unintentional loss, 10 pounds in the prior year, or $5 \%$ of body weight in the prior year (by direct measurement of weight) at follow-up. Exhaustion was measured using questions as indicated by a self-report on exhaustion. A weak handgrip strength was defined for female: $<17 \mathrm{~kg}$ for body mass index $(\mathrm{BMI})<23,<7.3 \mathrm{~kg}$ for BMI 23.1-26, <18 kg for BMI 26.1-29, and $<21 \mathrm{~kg}$ for $\mathrm{BMI}>29$, while for male: $<29 \mathrm{~kg}$ for $\mathrm{BMI}<24,<30 \mathrm{~kg}$ for BMI 24.1-26, <30 kg for BMI 26.1-28, and $<32 \mathrm{~kg}$ for $\mathrm{BMI}>28$. Slowness was identified based on the duration time recorded for walking a distance of 15 feet $(4.57 \mathrm{~m})$ at the usual pace walking test. A normal reference for the test stratified by gender and body height (female: $>7 \mathrm{~s}$ for height $<159 \mathrm{~cm},>6 \mathrm{~s}$ for height $>159 \mathrm{~cm}$; while for male: $>7 \mathrm{~s}$ for height $<173 \mathrm{~cm}$, and $>6 \mathrm{~s}$ for height $>173 \mathrm{~cm}$ ). Low physical activity was defined if the activity is $<270 \mathrm{Kcal}$ on the activity scale (18 items) in females, and $<383 \mathrm{Kcal}$ on the activity scale (18 items) in males. The final sum scores ranged from 0 to 5 ( 1 point for each criterion), participants then classified as frail if a minimum of 3 of 5 scores were met; whereas pre-frail individuals have score $1-2$, a non-frail individual met none of them [17].

\section{Flow cytometry: $C D 4 / C D 8$ ratio}

Following classifying the participants into frail and robust groups, blood samples were taken after 8-10 $\mathrm{h}$ of fasting and resting a night 
before. The samples were drawn from cubital veins between 6:00 and 8:00 AM. Approximately, $3 \mathrm{~mL}$ of blood was collected in ethylenediaminetetraacetic acid-anticoagulated tubes, stored in a cooler box, and delivered to the Laboratory of Biomedical Sciences at the University of Brawijaya within $2 \mathrm{~h}$ of taking the sample. The samples then analyzed for CD4 and CD8 T-cells using anti-human CD4 and CD8 antibody (cat\#561842 and cat\#561949, respectively) on BD FACSCalibur flow cytometer; and plasma IL-6 level was measured using enzyme-linked immunosorbent (ELISA) MAX ${ }^{\text {TM }}$ Deluxe Set Human IL-6 (cat\# 430504), an ELISA based assay.

\section{Statistical analysis}

Descriptive statistics were used to describe the study population. Data obtained were then statistically analyzed using an independent t-test to compare both groups and Pearson's correlation to determine the associations between IL- 6 and the CD4/CD8 ratio with frailty. Graphics were then presented using GraphPad Prism 5.0.

\section{Results}

The baseline characteristics of the present study consisted of 55 females (86\%) and 9 males (14\%). Most of them had education levels under the tertiary level (84\%), abnormal BMI (70\%) (such as low, overweight, and obese), and abnormal blood pressure (85.9\%) (Table 1).

Table 1: Baseline characteristic of 64 older subjects

\begin{tabular}{ll}
\hline Characteristics & Descriptive, $\mathrm{n}(\%)$ \\
\hline Sex & \\
$\quad$ Female & $55(86)$ \\
$\quad$ Male & $9(14)$ \\
Level of education & \\
$\quad$ Low education & $54(84.4)$ \\
$\quad$ Advanced education & $10(15.6)$ \\
BMl & \\
$\quad$ Other than normal weight & $45(70)$ \\
$\quad$ Normal weight & $19(30)$ \\
Blood pressure & \\
$\quad$ Other than normal tension & $55(85.9)$ \\
Normal tension & $9(14.1)$ \\
\hline BMl: Bodymass index &
\end{tabular}

The statistical analysis revealed significant differences in age and level of education (Figure 1). The participants were then categorized into two age groups: $65-73$ years and $>73$ years. Analysis using t-test and a Mann-Whitney test showing significant differences in age and level of education ( $p=0.001$ and $p<0.001$, respectively), implying that the frail group tends to have older age and lower level of education. However, IL-6 levels and CD4/CD8 ratios were not significantly different between the two groups (Supplementary Table 1 and Figure 2).

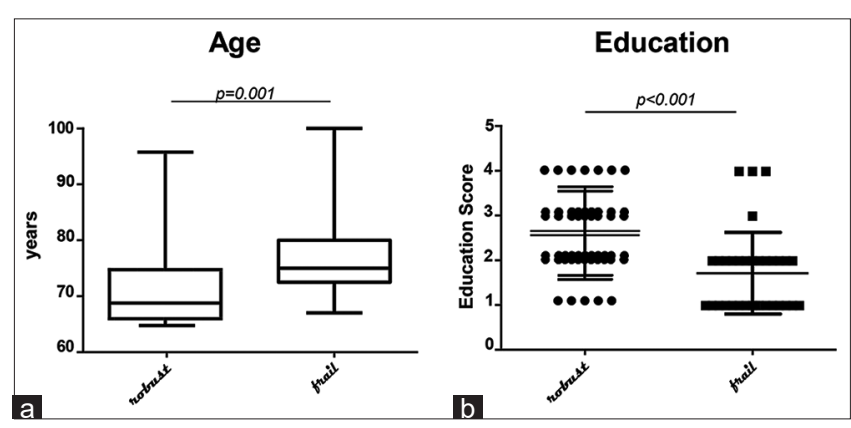

Figure 1: Older age (a) and lower education (b) are more common in the frail group than in the robust group $(p=0.001$ and $p<0.001$, respectively)

The frail group was dominated by females, possibly due to most of the participants in the present study were female. The blood pressure profile was showing various stages of hypertension with only a few percentages having normal tension (Supplementary Figure 1). Further analysis of frailty parameters revealed that BMI was the only common variable between the two groups (Supplementary Figure 2).

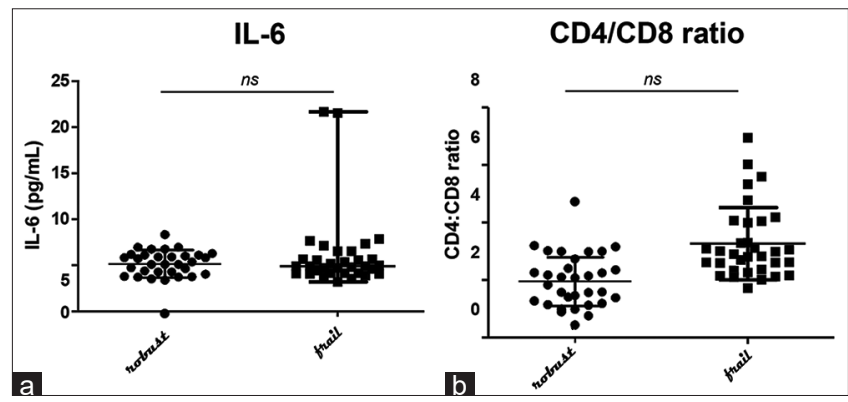

Figure 2: Plasma level of interleukin (IL)-6 tends to increase equally in both groups $(p=0.001)$ (a) and no differences can be observed in cluster of differentiation (CD)4/CD8 ratio between the two groups $(<0.001)(b)$

\section{Discussion}

\section{IL-6 and frailty}

The study of frailty is still in its infancy, and its analysis and description remain a challenge. However, this analysis is important to shedding light on the multiple mechanisms involved in the pathogenesis of frailty and the factors that contribute to its onset and status [18]. Many studies, such as a meta-analysis including 32 cross-sectional studies and 23,910 older participants [19], have reported increasing levels of IL-6 in frail and pre-frail elderly compared with the robust elderly, as part of the inflammaging process. A mouse model with inducible IL-6 expression (IL-6 TET-ON/+ mice) that enables overexpression of IL-6 following stimulation with doxycycline administrated in food led to an increase in frailty as measured by a 30-point murine clinical frailty index [20]. A Chinese study that investigates the association of inflammatory 
mediators and frailty and their relationship with physical function suggests that inflammatory mediators IL-6 might be biomarkers for frailty and decreased physical function in older adults [21].

In the present study, the mean IL-6 value of the participants was higher than the normal value from the reference $(1.4 \mathrm{pg} / \mathrm{mL}$ in males and $1.1 \mathrm{pg} / \mathrm{mL}$ in females). This difference could be due to the limited sample size of the preliminary study, which did not explore the factors that influence plasma IL-6 levels. Compared with the robust participants, our data indicate that mean IL-6 levels in the frail participants were not significantly different. This lack of difference could be explained by Allen, who reported that blood levels of inflammatory cytokines and acute-phase proteins were reduced by exercise [22]. However, another study suggested an elevation of the pro-inflammatory cytokines IL-6 that were more evident after intense exercise bouts [23].

Some researchers have found that other factors can also cause increased IL-6 levels. Increased levels of serum and/or tumor IL-6 are seen in several malignant conditions, both hematopoietic malignancies and solid tumors, and high IL-6 level is generally associated with a poorer outcome [24]. Overproduction of IL-6 also responsible for the pathogenesis of autoimmune inflammatory diseases and IL-6 blockade therapy can rectify these underlying immunological abnormalities in autoimmunity [25]. Systemic upregulation of IL-6 also occurs during the acute phase of infection [26]. Circulating IL-6 is elevated in asthmatic patients, both active disease or intrinsic asthma [27], and also increases in allergic patients [28]. The elimination of any of these conditions is needed for future research.

Furthermore, the upregulation of IL-6 in the present study may be caused by the distribution of BMI, as most of the participants were overweight and obese. Circulating levels of IL-6 were significantly higher in subjects with overweight and obesity [29]. In obesity, macronutrients excess in adipose tissues stimulates the release of inflammatory adipokines such as IL-6, TNF- $\alpha$, monocyte chemoattractant protein-1, and resistin leading to a state of chronic inflammation in obese subjects [30]. Another study also suggested that the enlargement of the white adipose tissue induces mechanical as well as endoplasmic reticulum stress in adipocytes, leading to the release of free fatty acids and inflammatory cytokines like TNF- $\alpha$ and IL- 6 , resulting in a local and systemic low-grade inflammation [31].

A study in a population of Spanish older adults found progressive increases in all inflammatory mediator concentrations with frailty by Marcos-Pérez et al. These increases were especially notable for IL-6 and soluble TNF-receptor II and suggest the predictive value of these biomarkers for frailty. Although, results from the current study revealed limited associations between frailty and the lymphocyte subsets assessed, data obtained for the inflammatory mediators provide further support to the involvement of inflammaging in frailty [32].

\section{The CD4/CD8 ratio and frailty}

CD4 helper/inducer cells and CD8 cytotoxic/suppressor cells are 2 phenotypes of $\mathrm{T}$ lymphocytes, characterized by distinct surface markers and functions that mostly reside in lymph nodes but also circulate in the blood. The CD4/CD8 ratio 1.5 and 2.5 are generally considered normal; however, a wide heterogeneity exists because sex, age, ethnicity, genetics, exposures, and infections may all impact the ratio. Normal ratios can invert through isolated apoptotic or targeted cell death of circulating CD4 cells, expansion of CD8 cells, or a combination of both phenomena. A low or inverted CD4/CD8 ratio is an immune risk phenotype and is associated with altered immune function, immune senescence, and chronic inflammation in both HIV-infected and uninfected populations [15].

The mean CD4/CD8 ratios of the participants in this study were $>1$, and the comparison of both groups showed no significant differences. Similar results were found in a longitudinal study on the Singaporean elderly. CD4/CD8 ratios did not correlate with frailty but had prognostic value when the mortality risk of the participants was assessed [14]. Further studies are needed to confirm whether the CD4/CD8 ratios correlate with frail elderly in Indonesia and whether longitudinal studies indicate a prognostic value for mortality risk.

Significant higher mortality rates were observed among the elderly with an inverted CD4:CD8 ratio and a low nonspecific $T$ proliferation regardless of their health status. The inversion of the CD4/CD8 ratio has been associated with features of premature immunosenescence across different age groups [33]. When examining previous studies, although the sample size was small (13 frail vs. 13 non-frail participants), De Fanis et al. found a significant association between increased CD8+ and decreased CD4+ cell percentages in the frail group compared with the non-frail group [34]. Furthermore, a 2005 study found a significantly increased number of CD8+ $T$ lymphocytes and CD8+CD28- lymphocytes in frail women versus pre-frail and non-frail women (Semba et al., 2005). A Spain study in the frail group concluded that the frequency of CD8+CD28-CD57+ was significantly elevated in comparison with the non-frail group [35], [36].

Some conditions also cause reduced CD4/CD8 ratio. The patients with tuberculosis [37] and HIV infection [38] show a reduced CD4+/CD8+ ratio. Furthermore, while an abnormal ratio is not uniformly present in all autoimmune diseases, a decreased CD4/CD8 ratio is consistently seen in systemic lupus erythematosus [39]. A recent prospective study showed a reduced CD4/CD8 ratio in a population of 96 elderly patients who were hospitalized for primary chronic heart failure [15]. An increase in CD4/CD8 ratio has been observed in patients with various cancers, such as in breast cancer [40], cervical cancer [41], gastric cancer [42], and colorectalcancer [43]. 


\section{Frailty, age, and education levels}

The results, from our study, indicated that age and education levels varied significantly between the robust and frail groups. As demonstrated in previous studies, age plays a role in frailty development [44]. That result also in line with previous research. A study group in Malaysia concluded that there was a significantly higher prevalence of frailty among old older age group (60-74 years) (34.2\%) compared to those from young older age group (>75 years) (7.7\%; $\mathrm{p}<0.001$ ) (Mohd Hamidin et al., 2018) [49]. Another study in Indonesia also stated that frailty was associated with age and identified prognostic factors for frailty state worsening in 12 months were being 70 years or older [45]. Frailty development could be caused by longer exposure to stress conditions such as infection, physical stress, and oxidative stress, which continue as people age. These conditions cause the body to respond with increased proinflammatory cytokine production, which eventually results in frailty [17].

Education levels were also significantly associated with frailty, which was higher in those of all age groups with secondary and primary or lower education compared with those having tertiary education [46]. A cross-sectional study in Brazil involving 540 older adults stratified into groups based on formal education suggests that limited education had a gradient association with cognitive performance, functional disability, and frailty [47]. Education levels can play a role in frailty development in communitybased elderly through their lack of awareness of healthy choices, a less hygienic lifestyle, less adequate and balanced nutrition, and a lack of knowledge about chronic diseases and their management. Hoogendijk had reported that low levels of education and low economic status limit access to information and adequate health services, which contributes to the development of frailty and its progress to disability [48]. Notably, nutritional status, through its effects on cellular metabolism, can also influence the immune system. For example, hormones and cytokines (mainly adipocytokine levels), immune cell populations and function, and increasing inflammation contribute to frailty [18].

There are three limitations of this study. First, there was a heterogeneous distribution of the participants in terms of sex, age, level of education, and BMI. Second, other conditions that can interfere with IL-6 levels and CD4/CD8 ratios were not completely excluded because of a lack of full examinations due to economic constraints placed on the study. Finally, the cross-sectional design of the study might not be adequate for drawing definitive conclusions on the effect of IL-6 or the CD4/CD8 ratio on the development of frailty.

\section{Conclusion}

This present study demonstrated that mean levels of plasma IL-6 were both equally increased in the two groups, with no statistically significant differences between them. Mean CD4/CD8 ratios were within normal limits, and there were no significant differences between the two groups. However, differences in age and education levels were significant. Plasma IL-6 and the CD4/CD8 ratio appear to not affect frailty. We suggest that further examinations of the participants need to be conducted in future studies to exclude factors that are known to interfere with IL-6 levels and the CD4/CD8 ratio.

\section{References}

1. Sander M, Oxlund B, Jespersen A, Krasnik A, Mortensen EL, Westendorp RG, et al. The challenges of human population ageing. Age Ageing. 2015;44(2):185-7. http://doi.org/10.1093/ ageing/afu189

PMid:25452294

2. United Nations. World Population Prospect 2019: Ten Key Findings. Department of Economic and Social Affairs World Population Prospects; 2019.

3. Satake S, Arai H. Chapter 1 frailty: Definition, diagnosis, epidemiology. Geriatr Gerontol Int. 2020;20(Suppl 1):7-13. http://doi.org/10.1111/ggi.13830

PMid:32050303

4. Grabovac I, Haider S, Mogg C, Majewska B, Drgac D, Oberndorfer $\mathrm{M}$, et al. Frailty status predicts all-cause and cause-specific mortality in community dwelling older adults. J Am Med Dir Assoc. 2019;20(10):1230-5.e2. http://doi. org/10.1016/j.jamda.2019.06.007

PMid:31351859

5. Ofori-Asenso R, Chin KL, Mazidi M, Zomer E, llomaki J, Zullo AR, et al. Global incidence of frailty and prefrailty among community-dwelling older adults: A systematic review and meta-analysis. JAMA Netw Open. 2019;2(8):e198398. http:// doi.org/10.1001/jamanetworkopen.2019.8398 PMid:31373653

6. Satake S, Shimada H, Yamada M, Kim H, Yoshida H, Gondo Y, et al. Prevalence of frailty among community-dwellers and outpatients in Japan as defined by the Japanese version of the Cardiovascular Health Study criteria. Geriatr Gerontol Int. 2017;17(12):2629-34. http://doi.org/10.1111/ggi.13129 PMid:29265757

7. Setiati S, Soejono $\mathrm{CH}$, Harimurti K, Dwimartutie N, Aryana IG, Sunarti $\mathrm{S}$, et al. Frailty and its associated risk factors: First phase analysis of multicentre Indonesia longitudinal aging study. Front Med (Lausanne). 2021;8:658580. http://doi.org/10.3389/ fmed.2021.658580

PMid:33996862

8. Sunarti S, Hariyanti T, Chriswantara RT. Physical activities, sitting time and frailty syndrome in elderly (a cross sectional study among elder person by fried criteria). MNJ. 2018;4(2):5964. https://doi.org/10.21776/ub.mnj.2018.004.02.3.

9. Bektas A, Schurman SH, Sen R, Ferrucci L. Aging, inflammation and the environment. Exp Gerontol. 2018;105:10-8. http://doi. 
org/10.1016/j.exger.2017.12.015

PMid:29275161

10. Dinh HC, Bautmans I, Beyer I, Mets T, Onyema OO, Forti LN et al. Association between immunosenescence phenotypes and pre-frailty in older subjects: Does cytomegalovirus play a role? J Gerontol Ser A Biol Sci Med Sci. 2019;74(4):480-8. http://doi. org/10.1093/gerona/gly135

PMid:29924317

11. Vatic M, von Haehling S, Ebner N. Inflammatory biomarkers of frailty. Exp Gerontol. 2020;133:110858.

12. Ferrucci L, Fabbri E. Inflammageing: Chronic inflammation. Nat Rev Cardiol. 2018;15(9):505-22. http://doi.org/10.1038/ s41569-018-0064-2

PMid:30065258

13. Cardoso AL, Fernandes A, Aguilar-Pimentel JA, de Angelis MH, Guedes JR, Brito MA, et al. Towards frailty biomarkers: Candidates from genes and pathways regulated in aging and age-related diseases. Ageing Res Rev. 2018;47:214-77. http:// doi.org/10.1016/j.arr.2018.07.004

PMid:30071357

14. Ng TP, Camous X, Nyunt MS, Vasudev A, Tan CT, Feng L, et al. Markers of T-cell senescence and physical frailty: Insights from Singapore longitudinal ageing studies. npj Aging Mech Dis. 2015;1:15005. http://doi.org/10.1038/npjamd.2015.5 PMid:28721254

15. McBride JA, Striker R. Imbalance in the game of T cells: What can the CD4/CD8 T-cell ratio tell us about HIV and health? PLoS Pathog. 2017;13(11):e1006624. http://doi.org/10.1371/journal. ppat. 1006624 PMid:29095912

16. Fried LP, Tangen CM, Walston J, Newman AB, Hirsch $C$, Gottdiener J, et al. Frailty in older adults: Evidence for a phenotype. J Gerontol. 2001;56(3):146-56. http://doi. org/10.1093/gerona/56.3.m146 PMid:11253156

17. Xue QL. The frailty syndrome: Definition and natural history. Clin Geriatr Med. 2011;27(1):1-15. http://doi.org/10.1016/j. cger.2010.08.009

PMid:21093718

18. Pansarasa O, Pistono C, Davin A, Bordoni M, Mimmi MC Guaita A, et al. Altered immune system in frailty: Genetics and diet may influence inflammation. Ageing Res Rev. 2019;54:100935. http://doi.org/10.1016/j.arr.2019.100935 PMid:31326616

19. Soysal P, Stubbs B, Lucato P, Luchini C, Solmi M, Peluso R, et al. Inflammation and frailty in the elderly: A systematic review and meta-analysis. Ageing Res Rev. 2016;31:1-8. http://doi. org/10.1016/j.arr.2016.08.006

PMid:27592340

20. Jergovic M, Thompson-Ryder HL, Asghar A, Nikolich-Zugich J. The role of Interleukin-6 in age-related frailty syndrome. J Immunol. 2020;204(Suppl 1):59.17.

21. Ma L, Sha G, Zhang Y, Li Y. Elevated serum IL-6 and adiponectin levels are associated with frailty and physical function in Chinese older adults. Clin Interv Aging. 2018;13:2013-20. http:// doi.org/10.2147/CIA.S180934 PMid:30410318

22. Allen S. Systemic inflammation in the genesis of frailty and sarcopenia: An overview of the preventative and therapeutic role of exercise and the potential for drug treatments. Geriatrics. 2017;2(1):6. http://doi.org/10.3390/geriatrics2010006 PMid:31011016

23. Cerqueira É, Marinho DA, Neiva HP, Lourenço O. Inflammatory effects of high and moderate intensity exercise a systematic review. Front Physiol. 2020;10:1550. http://doi.org/10.3389/ fphys.2019.01550

PMid:31992987

24. Johnson DE, O'Keefe RA, Grandis JR. Targeting the IL-6/ JAK/STAT3 signalling axis in cancer. Nat Rev Clin Oncol. 2018;15(4):234248. http://doi.org/10.1038/nrclinonc.2018.8 PMid:29405201

25. Uciechowski P, Dempke WC. Interleukin-6: A masterplayer in the cytokine network. Oncology (Switzerland). 2020;98(3):131-7. http://doi.org/10.1159/000505099

PMid:31958792

26. Velazquez-Salinas L, Verdugo-Rodriguez A, Rodriguez LL, Borca MV. The role of interleukin 6 during viral infections. Front Microbiol. 2019;10:1057. http://doi.org/10.3389/ fmicb.2019.01057

PMid:31134045

27. Poynter ME, Irvin CG. Interleukin-6 as a biomarker for asthma: Hype or is there something else? Eur Respir J. 2016;48(4):979-81. http://doi.org/10.1183/13993003.01597-2016 PMid:27694408

28. Neeland IJ, Eliasson B, Kasai T, Marx N, Zinman B, Inzucchi SE, et al. The Impact of empagliflozin on obstructive sleep apnea and cardiovascular and renal outcomes: An exploratory analysis of the EMPA-REG outcome trial. Diabetes Care. 2020;43(12):3007-15. http://doi.org/10.2337/dc20-1096 PMid:33004464

29. El-Mikkawy DM, EL-Sadek MA, EL-Badawy MA, Samaha D. Circulating level of interleukin-6 in relation to body mass indices and lipid profile in Egyptian adults with overweight and obesity. Egypt Rheumatol Rehabil. 2020;47(1):7. https://doi.org/10.1186/ s43166-020-00003-8

30. Ellulu MS, Patimah I, Khaza'ai H, Rahmat A, Abed Y. Obesity and inflammation: The linking mechanism and the complications. Arch Med Sci. 2017;13(4):851-63. http://doi.org/10.5114/ aoms.2016.58928

PMid:28721154

31. Kern L, Mittenbühler MJ, Vesting $A J$, Ostermann $A L$, Wunderlich CM, Wunderlich FT. Obesity-induced TNF $\alpha$ and IL-6 signaling: The missing link between obesity and inflammationdriven liver and colorectal cancers. Cancers (Basel). 2018;11(1):24. http://doi.org/10.3390/cancers11010024 PMid:30591653

32. Marcos-Pérez D, Sánchez-Flores M, MasedaA, Lorenzo-López L, Millán-Calenti JC, Gostner JM, et al. Frailty in older adults is associated with plasma concentrations of inflammatory mediators but not with lymphocyte subpopulations. Front Immunol. 2018;9:1056. http://doi.org/10.3389/fimmu.2018.01056 PMid:29868017

33. Müller MJ, Geisler C, Pourhassan M, Glüer CC, Bosy-Westphal A. Assessment and definition of lean body mass deficiency in the elderly. Eur J Clin Nutr. 2014;68(11):1220-7. http://doi.org/10.1038/ejcn.2014.169 PMid:25139559

34. De Fanis U, Wang GC, Fedarko NS, Walston JD, Casolaro V, Leng SX. T-lymphocytes expressing CC chemokine receptor-5are increased in frail older adults. JAm Geriatr Soc. 2008;56(5):904-8. http://doi.org/10.1111/j.1532-5415.2008.01673.x PMid: 18384587

35. Semba RD, Margolick JB, Leng S, Walston J, Ricks MO, Fried LP. T cell subsets and mortality in older community-dwelling women. Exp Gerontol. 2005;40(1-2):81-7. http://doi.org/10.1016/j. exger.2004.09.006 PMid:15664735

36. Álvarez $S$, Brañas $F$, Sánchez-Conde $M$, Moreno $S$, López-Bernaldo de Quirós JC, Muñoz-Fernández MÁ. Frailty, 
markers of immune activation and oxidative stress in HIV infected elderly. PLoS One. 2020;15(3):e0230339. http://doi. org/10.1371/journal.pone.0230339

PMid:32187205

37. Yin Y, Qin J, Dai Y, Zeng F, Pei H, Wang J. The CD4+/CD8+ ratio in pulmonary tuberculosis: Systematic and meta-analysis article. Iran J Public Health. 2015;44(2):185-93.

PMid:25905052

38. Francis-Morris A, Mackie NE, Eliahoo J, Ramzan F, Fidler S, Pollock KM. Compromised CD4:CD8 ratio recovery in people living with HIV aged over 50 years: An observational study. HIV Med. 2020;21(2):109-18. http://doi.org/10.1111/hiv.12800 PMid:31617962

39. Alegria GC, Gazeau P, Hillion S, Daïen Cl, Cornec DY. Could lymphocyte profiling be useful to diagnose systemic autoimmune diseases? Clin Rev Allergy Immunol. 2017;53(2):219-36. http:// doi.org/10.1007/s12016-017-8608-5

PMid:28474288

40. Yang X, Ren H, Sun Y, Shao Y, Zhang L, Li H, et al. Prognostic significance of CD4/CD8 ratio in patients with breast cancer. Int J Clin Exp Pathol. 2017;10(4):4787-93.

41. Li C, Liu W, Cheng Y. Prognostic significance of metastatic lymph node ratio in squamous cell carcinoma of the cervix. Onco Targets Ther. 2016;9:3791-7. http://doi.org/10.2147/OTT. S97702

PMid:27382315

42. Lorenzon L, Mercantini P, Ferri M, La Torre M, Sparagna A, Balducci $G$, et al. Lymph-node ratio classification strongly correlates with cancer survivals of patients who underwent r0 resection for gastric cancer with more than 15 nodes harvested. Eur Surg Res Eur Chir Forschung Rech Chir Eur. 2014;53(1-4):1-10. http://doi.org/10.1159/000360937 PMid:24854388

43. Chen YL, Wang CY, Wu CC, Lee MS, Hung SK, Chen WC, et al. Prognostic influences of lymph node ratio in major cancers of Taiwan: A longitudinal study from a single cancer center. J Cancer Res Clin Oncol. 2015;141(2):333-43. http://doi. org/10.1007/s00432-014-1810-4

\section{PMid:25169194}

44. Santos-Eggimann B, Cuénoud $P$, Spagnoli J, Junod J. Prevalence of frailty in middle-aged and older community-dwelling Europeans living in 10 countries. J Gerontol A Biol Sci Med Sci. 2009;64(6):675-81. http://doi. org/10.1093/gerona/glp012

PMid: 19276189

45. Setiati S, Laksmi PW, Aryana IG, Sunarti S, Widajanti N, Dwipa L, et al. Frailty state among Indonesian elderly: Prevalence, associated factors, and frailty state transition. BMC Geriatr. 2019;19(1):182. http://doi.org/10.1186/s12877-019-1198-8 PMid:31269921

46. Franse CB, Van Grieken A, Qin L, Melis RJ, Rietjens JA, Raat $\mathrm{H}$. Socioeconomic inequalities in frailty and frailty components among community-dwelling older citizens. PLoS One. 2017;12(11):e0187946. http://doi.org/10.1371/journal. pone. 0187946

PMid:29121677

47. Brigola AG, da Alexandre TS, Inouye K, Yassuda MS, Pavarini SC, Mioshi E. Limited formal education is strongly associated with lower cognitive status, functional disability and frailty status in older adults. Dement Neuropsychol. 2019;13(2):216-24

48. Hoogendijk EO, Van Hout HP, Heymans MW, Van Der Horst HE, Frijters DH, Broese MI, et al. Annals of epidemiology explaining the association between educational level and frailty in older adults: Results from a 13-year longitudinal study in the Netherlands. Ann Epidemiol. 2014;24(7):538-44.e2.

49. Mohd Hamidin FA, Adznam SN, Ibrahim Z, Chan YM, Abdul Aziz $\mathrm{NH}$. Prevalence of frailty syndrome and its associated factors among community-dwelling elderly in East Coast of Peninsular Malaysia. SAGE Open Med. 2018;6:2050312118775581. https://doi.org/10.1177/2050312118775581

PMid:29872529 


\section{Supplementary}

Supplementary Table 1: Distribution of gender, age, level of education, body mass index (BMI), blood pressure, IL-6 level, and CD4/CD8 ratio between the frail and robust group. In bold the significant $P$ value are reported

\begin{tabular}{|c|c|c|c|c|c|c|c|}
\hline & \multicolumn{2}{|c|}{ Frail } & \multicolumn{2}{|c|}{ Robust } & \multicolumn{2}{|c|}{$\mathrm{Cl}(95 \%)$} & \multirow[t]{2}{*}{$p$} \\
\hline & $\mathrm{n}$ & $\%$ & $\mathrm{n}$ & $\%$ & Min & $\operatorname{Max}$ & \\
\hline \multicolumn{8}{|l|}{ Sex } \\
\hline Female & 26 & 40.6 & 29 & 45.3 & \multirow{3}{*}{$\begin{array}{l}0.10 \\
2\end{array}$} & 1.97 & \multirow[t]{2}{*}{0.474} \\
\hline & & & & & & 6 & \\
\hline Male & 6 & 9.4 & 3 & 4.7 & & & \\
\hline \multicolumn{8}{|l|}{ Age } \\
\hline$>73$ years & 22 & 34.4 & 9 & 14.1 & \multirow[t]{2}{*}{1.92} & \multirow[t]{2}{*}{16.4} & \multirow[t]{2}{*}{$0.001^{*}$} \\
\hline $65-73$ years & 10 & 15.6 & 23 & 51.6 & & & \\
\hline \multicolumn{8}{|l|}{ Level of education } \\
\hline Low education & 28 & 43.8 & 13 & 20.3 & \multirow{3}{*}{$\begin{array}{l}2.89 \\
3\end{array}$} & 36.1 & \multirow[t]{3}{*}{$<0.001^{*}$} \\
\hline & & & & & & 77 & \\
\hline $\begin{array}{l}\text { Advanced } \\
\text { education }\end{array}$ & 4 & 6.3 & 19 & 29.7 & & & \\
\hline \multicolumn{8}{|l|}{ Body mass index } \\
\hline Other than & 23 & 36 & 22 & 34.3 & \multirow{4}{*}{$\begin{array}{l}1.68 \\
2\end{array}$} & 13.9 & \multirow[t]{4}{*}{1.000} \\
\hline normal weight & & & & 8 & & 30 & \\
\hline Normal weight & 9 & 14 & 10 & 15.6 & & & \\
\hline & & & & 2 & & & \\
\hline \multicolumn{8}{|l|}{ Blood pressure } \\
\hline $\begin{array}{l}\text { Other than } \\
\text { normal tension }\end{array}$ & 25 & 78.1 & 30 & 93.8 & \multirow[t]{2}{*}{$\begin{array}{l}0.04 \\
5\end{array}$} & \multirow[t]{2}{*}{$\begin{array}{l}1.25 \\
1\end{array}$} & \multirow[t]{2}{*}{0.148} \\
\hline Normal tension & 7 & 21.9 & 2 & 6.3 & & & \\
\hline IL-6 & & $4.88(3.18-21.66)$ & & $5.11(0.00-8.36)$ & 0.92 & 1.43 & 0.936 \\
\hline CD4/CD8 ratio & & $1.91(0.77-5.99)$ & & $1.96(0.41-3.77)$ & 0.83 & 2.18 & 0.468 \\
\hline
\end{tabular}

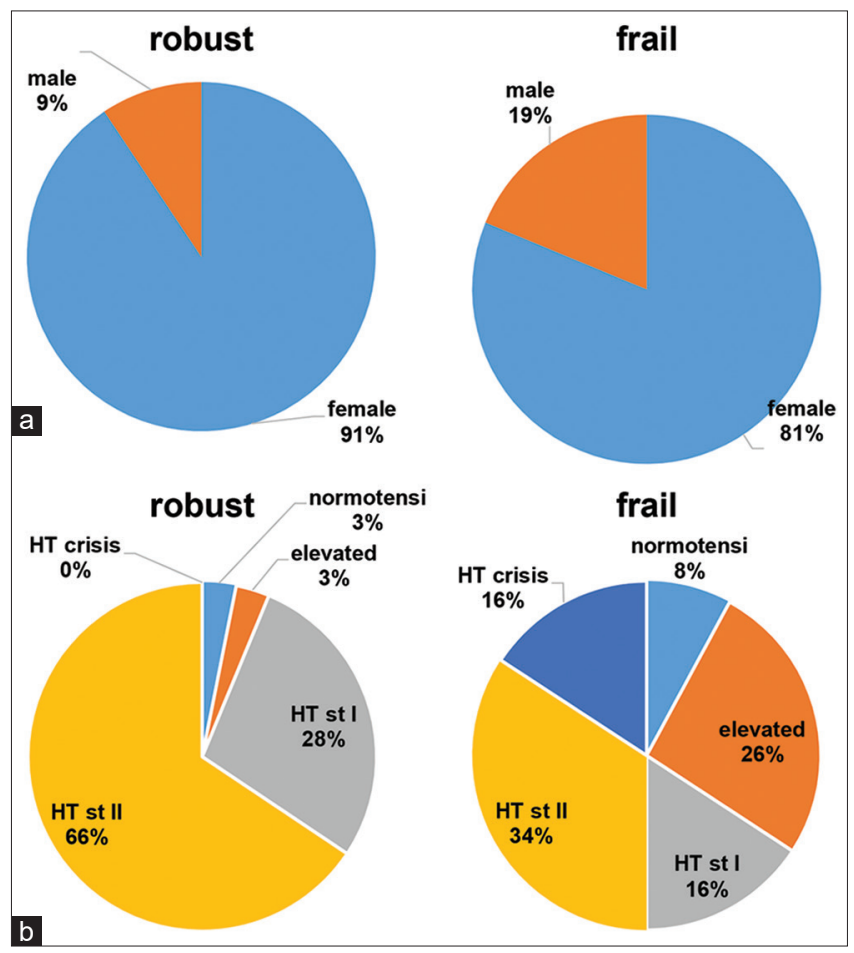

Supplementary Figure 1: Distribution of gender in robust and frail groups showing females predominately the subjects (a), and various hypertension stages among the subjects in both groups (b) 


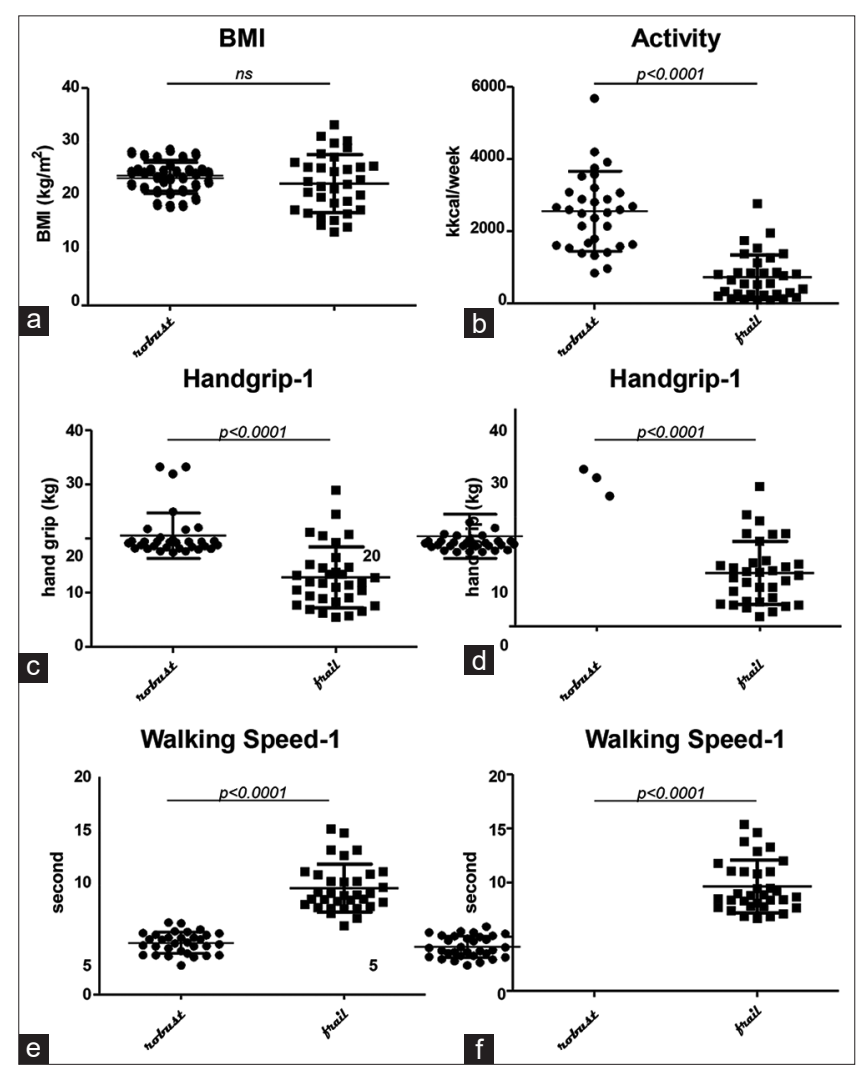

Supplementary Figure 2: Parameters of the Frailty Score between two groups: Body Mass Index (BMI) (a), activity (b), handgrip (c and d), and walking speed (e and f). The frail group showed lower activity, weaker handgrip, and slower walking speed. No significant difference in BMI between the two groups 